\title{
FAZ SENTIDO UMA BASE NACIONAL COMUM CURRICULAR?
}

\author{
Does a nationwide curriculum make sense?
}

Monica Ribeiro da SILVA

Universidade Federal do Paraná monicars03@gmail.com https://orcid.org/0000-0002-1729-8742

Juliana Zeggio MARTINEZ

Universidade Federal do Paraná

Núcleo de Assessoria Pedagógica jumartinez@ufpr.br

\author{
Alessandra Coutinho FERNANDES \\ Universidade Federal do Paraná \\ Núcleo de Assessoria Pedagógica \\ alessandrawiggers@gmail.com
}

\author{
Ana Paula BEATO-CANATO \\ Universidade Federal do Paraná \\ Núcleo de Assessoria Pedagógica \\ anabeatocanato@gmail.com
}

Professora Mônica Ribeiro da Silva realizou pós-doutorado na Faculdade de Educação da UNICAMP, doutorado em Educação: História, Política e Ciências Sociais pela Pontifícia Universidade Católica de São Paulo, mestrado em Educação: Fundamentos da Educação pela Universidade Federal de São Carlos e graduação em Pedagogia com habilitação em Administração Escolar pela Universidade Estadual Paulista Júlio de Mesquita Filho. Atualmente é professora na Universidade Federal do Paraná e atua nos cursos de formação de professores e no Programa de Pós-Graduação em Educação Mestrado e Doutorado. Mônica tem interesse no campo de pesquisa em Políticas Educacionais com ênfase para o Ensino Médio e na avaliação de políticas públicas, coordena o Grupo de Pesquisa Observatório do Ensino Médio e atua como vice-líder do Grupo de Pesquisa EMPesquisa - Pesquisas sobre Ensino Médio com sede na Unicamp. Além disso, é integrante do Movimento Nacional em Defesa do Ensino Médio e bolsista de Produtividade em Pesquisa do CNPq. 


\section{Juliana, Alessandra e Ana Paula:}

Monica, primeiramente, gostaríamos de agradecer imensamente por você aceitar participar desta entrevista. Estamos certas de que sua experiência e visão crítica nos ajudarão a ampliar nossa compreensão sobre a BNCC e este momento atual que a educação atravessa.

Temos conhecimento de seu envolvimento com questões oficiais e oficiosas referentes à educação em nosso país bem como do reconhecimento que a comunidade acadêmica e não acadêmica tem pelo seu trabalho, por seu engajamento e entusiasmo em busca de uma sociedade menos desigual e uma educação crítica e transformadora. Sabemos que você atuou de modo fortemente contrário à implementação da BNCC e gostaríamos que comentasse um pouco a respeito das razões dessa resistência.

\section{Mônica:}

Meu envolvimento com movimentos de ação de oposição à produção da BNCC tem se dado por duas vias: enquanto pesquisadora do campo do currículo e das políticas curriculares e como integrante do Movimento Nacional em Defesa do Ensino Médio. Essas vias se entrelaçam, pois o conhecimento de causa é necessário na construção da argumentação contrária. Ao longo dos últimos anos, a pesquisa acadêmica sobre como as escolas reagem aos textos oficiais, por exemplo, têm me mostrado que há um distanciamento entre o que prescreve um documento oficial e como as escolas, e principalmente os professores, se apropriam dele. A análise da produção das políticas curriculares, por outro lado, permite identificar os formuladores e o que esses pensam sobre educação, que concepções norteiam suas proposições, como concebem e tratam os “destinatários" dos currículos primordialmente elaborados em gabinetes. Temos passado por vários momentos em termos de formulação de políticas curriculares, mas o tratamento descontextualizado conferido às escolas tem sido algo que se repete. Lamentavelmente, o que se percebe é a proposição teórica de um currículo para uma escola "sem sujeitos", buscando a padronização de realidades muito distintas. As condições desiguais da oferta educacional, entretanto, impedem essa padronização. Uma vez que as comunidades, as práticas e os contextos escolares, bem como seus sujeitos, são múltiplos e heterogêneos, um projeto de padronização se torna uma irrealidade. No entanto, se produz um 
convencimento social acerca da necessidade dessa padronização, como se isso bastasse para melhorar a qualidade educacional. Na condição de especialista, para além da produção e divulgação do conhecimento acerca das políticas educacionais, faço coro com as entidades científicas e político-organizativos da área da educação que se contrapuseram à produção da $\mathrm{BNCC}$, seja porque do processo estiveram ausentes profissionais da educação e estudantes, seja porque o documento, em suas várias versões, ignora o que vem sendo praticado e produzido na área da educação.

\section{Juliana, Alessandra e Ana Paula:}

Em dezembro de 2017, após cerca de três anos desde a disponibilização de sua primeira versão, as etapas da BNCC referentes à Educação Infantil e ao Ensino Fundamental foram homologadas; posteriormente, em dezembro de 2018, a etapa referente ao Ensino Médio também foi homologada. Como você entende o contexto histórico que possibilitou que esse documento fosse implementada? Você percebe relação dessa política com grupos privados?

\section{Mônica:}

Há uma crença disseminada de que os problemas de qualidade na Educação Básica se resolveriam mediante reformas curriculares. Essa crença tem como efeito imediato o deslocamento de outras questões de fundo quando se trata da qualidade em educação. $O$ que estou querendo dizer é que problemas relativos à estrutura física e material das escolas; o pouco valor dado às licenciaturas; a desvalorização e precarização do trabalho docente, dentre outros, passam a ser secundarizados e se produz uma centralidade sobre os discursos das mudanças curriculares.

É preciso ressaltar também que as iniciativas dessa ordem no Brasil não são novas. Nos últimos 20 anos, tivemos duas ações nessa mesma direção. A produção dos Parâmetros Curriculares Nacionais (PCNs) na década de 90, e agora, a partir de 2014, da Base Nacional Comum Curricular (BNCC). Em ambos os casos, se deu imensa repercussão aos documentos normativos e quase nada se fez em termos de alteração nas condições de 
oferta das escolas, bem como em investimentos na formação de professores. O contexto, portanto, da produção do discurso oficial sobre as políticas curriculares é marcado por essa crença de que a qualidade da educação é diretamente dependente de documentos oficiais, produzidos em gabinetes e desatrelados dos contextos escolares.

Sobre as relações entre setores públicos e privados na formulação das políticas curriculares no Brasil, o que vemos é que ao longo dos últimos 20 anos essa relação vem se estreitando com presença cada vez maior dos institutos e das fundações ligadas ao campo empresarial que advogam a necessidade de reformas educacionais. O que ocorre é que essas instituições se autoproclamam especialistas em educação, oferecem soluções educacionais milagrosas, se apropriam de recursos públicos, e, ano após ano, o que vemos é a total ausência de resultados em termos de qualidade da educação no país.

\section{Juliana, Alessandra e Ana Paula:}

Apesar de sabermos que a BNCC é constituída por textos referentes a diversas áreas do conhecimento, a seu ver, qual seria a principal concepção de educação que embasa o documento?

\section{Mônica:}

Trata-se de uma concepção restrita de educação ancorada numa política curricular excessivamente prescritiva. A racionalidade instrumental que cerca a produção desse tipo de documento parte de um pressuposto amplamente posto à prova, qual seja, de que às escolas cabe tão somente cumprir o que está prescrito, ignorando que entre o currículo prescrito e o currículo "em ação" há um enorme distanciamento. Essa lógica instrumental toma o conhecimento como algo a ser transmitido e assimilado, como se todos os estudantes se apropriassem dos conteúdos e das experiências escolares da mesma forma, interagissem e reagissem da mesma maneira ao que lhes é oferecido. Ao contrário do que apregoam os adeptos a essa racionalidade, a escola é viva e não se resume à formalidade de aquisição de uma lista de conteúdos, ou seja, a formação humana não se aprisiona nos códigos da BNCC. 


\section{Juliana, Alessandra e Ana Paula:}

Quais avanços e retrocessos você identifica na BNCC, tomando como referência documentos oficiais que a precederam no âmbito nacional e estadual?

\section{Mônica:}

A meu ver, não há avanços. A realidade das quase 6 mil redes de ensino no Brasil é tão diversa e desigual que não faz o menor sentido um documento único de currículo oficial. Por mais que os formuladores da BNCC digam que "a base não é currículo", basta uma leitura do texto que se encontra ali, para perceber, sim, um currículo. E um currículo bem fechado, sem muita margem para transposições ou adequações a partir das diversas realidades locais das escolas. O caráter fechado desse texto se adéqua plenamente aos seus fins, o de servir de referência às avaliações em larga escala. Os ditos códigos presentes na BNCC, nas listagens de conteúdos em todas as áreas do conhecimento, convertem-se nos descritores das provas realizadas pelo Estado. Não por acaso a versão homologada da BNCC se ancora no resgate do discurso empoeirado das "competências", caudatária daquela lógica instrumental que mencionei acima, associada agora à formulação minuciosa de "objetivos de aprendizagem”. Não há avanço, portanto, quando se recorre à uma formulação de uma política curricular ancorada, fundamentalmente, na produção de mecanismos de controle sobre a educação, seus professores e estudantes.

\section{Juliana, Alessandra e Ana Paula:}

Quais você entende ser os principais desafios para a implementação da BNCC em nível nacional e no Estado do Paraná?

\section{Mônica:}

Da forma como vejo, não será implementada. Uma política curricular, seja ela mais, ou menos prescritiva, se depara com práticas curriculares consolidadas, com profissionais da educação que acumulam experiências, e que leem e interpretam de maneiras distintas as proposições presentes no documento oficial. Entre o que está proposto na BNCC e sua suposta implementação, tem pessoas, tem histórias, tem condições materiais, tem vida. A 
escola não é esse espaço neutro e morto como supõem os elaboradores dos textos normativos, especialmente como este da BNCC, produzido sem qualquer interlocução com as escolas.

\section{Juliana, Alessandra e Ana Paula:}

Como você vê a Resolução CNE/CP n. 2 de 20 de dezembro de 2019, que exige que os cursos de licenciatura se adéquem à BNCC?

\section{Mônica:}

Os cursos de licenciaturas necessitam, sim, de atenção. Precisam ser valorizados e reformulados naquilo que pecam em termos de formação de profissionais com condições plenas de tomar decisões sobre os processos pedagógicos. A formação desses profissionais não se faz sem que a eles se ofereça uma densa imersão nos fundamentos epistemológicos que permitem compreender toda a complexidade que cerca a formação humana e a educação escolar. Ao contrário, portanto, do que se apresenta na Resolução exarada pelo Conselho Nacional de Educação com base na BNCC, a licenciatura não possui centralidade no exercício repetitivo de uma prática sem teoria, tampouco se resume a decorar uma listagem de códigos. Com isso, estou enfatizando que da mesma forma como não acredito que a BNCC será implementada nas escolas, essa Resolução não será efetivada desta forma concreta nas licenciaturas. Novamente, há uma lacuna entre a política e os contextos de Educação - Básica e Superior.

\section{Juliana, Alessandra e Ana Paula:}

Além das políticas públicas, temos vivenciado muitas políticas oficiosas, que têm influenciado fortemente a educação em nosso país. Como você percebe que tais grupos surgem e atuam?

\section{Mônica:}

A ação das fundações empresariais, como já mencionado, não é recente. Fundação 
Lemann, Instituto Airton Senna, Instituto Unibanco, dentre outros, passam a se agrupar formando o Movimento Todos pela Educação e o Movimento pela Base Nacional Comum. A ação dessas empresas sobre a educação pública não é nova, porém, antigamente elas atuavam muito mais como assessores da implementação de programas junto às redes públicas de ensino. Mais recentemente, elas passam a agir por dentro das esferas de governo, na própria formulação da política educacional, como é o caso da BNCC. Podemos nos perguntar: o que ganham com isso? Por que um banco se interessa por educação? A meu ver, ganham duplamente, ao se valer de recursos públicos e ao impor um projeto formativo ligado a seus interesses. Com isso, se fragiliza o caráter público da educação pública, gerando um processo de privatização que possui várias faces.

\section{Juliana, Alessandra e Ana Paula:}

Você percebe relações entre as ações promovidas por grupos como o Escola sem Partido e a BNCC? Poderia falar um pouco sobre isso?

\section{Mônica:}

O movimento Escola sem Partido compõe um programa que, ao contrário do que propaga, nada tem de neutro. É um movimento marcado por uma ideologia conservadora e reacionária e que teve uma atuação junto aos formuladores da BNCC e acabou incidindo na produção daquilo que podemos chamar de ausências. A proibição, por exemplo, de que determinados assuntos estivessem presentes ou adquirissem a centralidade que mereceriam são resultado desse processo de ausências. Exemplo disso é o assunto gênero, ou como chamado pelos adeptos do movimento, "ideologia de gênero", ou, ainda, a temática das religiões. Nos dois casos, a ação do Escola sem Partido foi pela imposição de sua própria visão, conservadora e intolerante. Ao clamar pela "neutralidade dos conteúdos", o movimento trai a sim mesmo, mostrando sua face ideológica.

\section{Juliana, Alessandra e Ana Paula:}

Como você avalia as relações entre tais grupos e as concepções de educação mais 
difundidas no meio acadêmico e educacional contemporâneo? E qual o papel da universidade neste cenário?

\section{Mônica:}

Os grupos empresariais nem sempre são identificados pelas pessoas dentro das Universidades. Nesse sentido, é possível encontrar, por exemplo, professores formando novos profissionais da educação tomando a BNCC como algo a ser ensinado, memorizado, praticado, sem qualquer análise ou crítica acerca de seus formuladores e de suas intenções. Os grupos vinculados a movimentos como o Escola sem Partido possuem adeptos nas Universidades, pois estas, como de resto toda a sociedade, é composta por pessoas que possuem distintas visões de mundo. Sobre o papel das Universidades, uma vez ancorada na produção do conhecimento e no respeito ao pensamento divergente, nelas não há lugar, ou não deveria haver, para qualquer forma de preconceito, intolerância, negacionismo ou perseguição político-ideológica.

\section{Juliana, Alessandra e Ana Paula:}

Como você avalia influências da mídia bem como de grupos de whatsapp e fakenews no cenário educacional brasileiro atual? E como podemos lidar com essas influências?

\section{Mônica:}

A propagação e diversificação midiática, bem como a profusão das redes sociais, em escala global, ao mesmo tempo em que permitem a rapidez na veiculação de informações, possibilitam a disseminação de notícias falsas. Em sendo assim, adquire ainda mais relevância um projeto educacional que possibilite a autonomia intelectual e moral dos sujeitos, a capacidade de identificar esses processos de convencimento coletivo assentados na mentira e na deturpação proposital da realidade.

\section{Juliana, Alessandra e Ana Paula:}

Por fim, você gostaria de acrescentar algo, deixar algum recado especialmente para as educadoras e educadores de nosso país? 


\section{Mônica:}

Escrevo as respostas a esta entrevista em meio à pandemia da COVID-19. No Brasil, são quase 100 mil mortes e passamos dos 2 milhões e 700 mil infectados. O cenário é de incertezas quanto ao presente e quanto ao futuro. É nesse contexto que assistimos às pressões de governos e empresários pela volta às aulas presenciais. Os defensores das crianças nas escolas disseminam o argumento de que "vão ficar sem os conteúdos e serão prejudicadas". Vemos, aqui, a mesma racionalidade instrumental mencionada quando da referência à produção da BNCC. É preciso alertar, sempre, que escola não se resume ao cumprimento formal de dias letivos; que educação não é repasse de conteúdos; que os resultados educacionais não se medem nas provas. É preciso reivindicar o sentido profundo da educação. Seu caráter formativo e libertador. É preciso reafirmar o direito à vida, sem a qual, nada faz sentido.

\section{Juliana, Alessandra e Ana Paula:}

Agradecemos imensamente por sua disponibilidade em dialogar com a gente e por suas contribuições. 